\title{
On the stability of collusive price leadership*
}

\author{
Claude d'Aspremont, Alexis Jacquemin and Jean Jaskold Gabszewiczł \\ John Weymark $\ddagger$
}

\begin{abstract}
The gains from cartel formation and the stability of a dominant cartel are investigated for the price-leadership model. We show that there is a general interest in the establishment of a cartel with the competitive fringe reaping a disproportionate share of the benefits. In contrast to results involving a continuum of firms, with a finite number of firms (each with the same cost curve) there is always a stable dominant cartel.

A propos de la stabilité d'une structure de marché caractérisée par la collusion de firmes dominantes pour établir un leadership de prix. Le mémoire étudie les gains dérivés de la formation d'un cartel et la stabilité d'un cartel dominant dans le cadre d'un modèle de leadership de prix de la firme dominante. On montre qu'il y a un intérêt général à créer un cartel même si les firmes satellites à la périphérie du cartel ramassent une part plus que proportionnelle des bénéfices. Contrairement à ce que l'on observe quand on est en présence d'un continuum de firmes, quand leur nombre est fini - chacune avec la même courbe de coûts - il y a toujours un cartel dominant stable.
\end{abstract}

\footnotetext{
${ }^{*}$ We have had the benefit of comments from Cecilia Conrad, Yair Tauman, and the referees.

Reprinted from Canadian Journal of Economics/Revue canadienne d'Economique, XVI(1), February/février 1983.

${ }^{\dagger}$ Université catholique de Louvain.

${ }^{\ddagger}$ University of British Columbia.
} 


\section{Introduction}

Among the forms of market organization for which some degree of collusion is assumed, the priceleadership model has been widely used and is considered to have considerable support. ${ }^{1}$ For this model a dominant firm or group of firms is supposed to impose a selling price on a competitive fringe of small producers. Although the empirically oriented literature has extensively analysed the degree to which this behaviour corresponds to industry practice, no parallel theoretical development has been made on the stability of this market arrangement. More specifically, the following questions seem to be in order. Is the observed persistence of this type of collusive behaviour implied by the pure theoretical model? What are the gains of collusive price-leadership for the members of the dominant cartel and for the members of the competitive fringe? Is there a stable size for the dominant cartel for which the agreed market organization can be viewed as profitable, in some sense, by all producers? ${ }^{2}$

In the next section we develop our model and consider the benefits to be gained from cartel formation. Assuming that all firms have identical cost curves, we shall show that members of both the dominant cartel and the competitive fringe benefit from the cartel's existence and that per-firm profits in the cartel increase with the size of the cartel. The gains from cartelization are not spread evenly, however; by free-riding, fringe firms enjoy higher profits than cartel members.

In the following section we investigate the implications of these results for the stability properties of the price-leadership model. With a finite number of firms (each with the same cost curve), we demonstrate that it is always possible to find a stable cartel. In contrast, with a continuum of firms there is always an incentive for a cartel member to join the competitive fringe independent of the size of the cartel; this market arrangement is unstable. ${ }^{3}$

\footnotetext{
${ }^{1}$ Markham (1951) formulated the concept of collusive price leadership. For a general analysis see Scherer (1970, chap. 6).

${ }^{2}$ In one of the few theoretical studies of the price-leadership model, Worcester (1957) assumed that there was a single dominant firm and argued that its market share would be eroded by entry into the industry. He did not consider the issues raised in this paper.

${ }^{3}$ An analogous conclusion has been reached in the context of pure exchange economies for which similar stability analyses have been conducted. See Aumann (1973) and Jaskold Gabszewicz and Drèze (1971).
} 
In the third section we present some remarks aimed at integrating our findings in the finite and in the continuum cases. In the final section we summarize our conclusions, discuss some limitations of our model, and suggest a number of extensions to our analysis.

\section{Gains from cartel formation}

We consider an industry composed of a fixed finite number of firms $n$ producing a homogeneous output. Each firm has an identical differentiable cost function $C(q)$ with marginal cost $C^{\prime}(q)$ positive and increasing in output $q$. The demand function for the industry's product $D(p)$ is a non-negative differentiable function of the price $p$ with $D^{\prime}(p)<0$.

In the price-leadership model it is supposed that $k$ firms decide to combine and form a cartel; the remaining $n-k$ firms constitute the competitive fringe. Members of the competitive fringe take the price as given by the dominant cartel and choose their production level by setting marginal cost equal to this price. Thus, as the price is varied, a competitive firm's output response is given by its supply function $S(p)$.

Members of the dominant cartel are assumed to choose the price that maximizes their joint profit, given the supply decisions of the competitive fringe. This is equivalent to having the cartel behave as a monopolist with respect to the residual demand curve, assumed non-negative and decreasing in $p$,

$$
R D(k, p) \equiv D(p)-(n-k) S(p) .
$$

Since all firms are identical, the cartel will want to spread production uniformly among its members. No redistribution of profits among firms is allowed. At this joint profit maximum for the cartel, the price is $p^{*}(k)$, each firm in the cartel produces $q_{d}^{*}(k)$ and receives profits $\pi_{d}(k)$, while each firm in the competitive fringe produces $q_{c}^{*}(k)$ and receives profits $\pi_{c}(k)$. If $k=0$, the industry is competitive; we let $p_{\text {comp }} \equiv p^{*}(0)$ and $\pi_{\text {comp }} \equiv \pi_{c}(0)$.

The gains from cartel formation are summarized in the following propositions:

Proposition $1 \pi_{d}(k)<\pi_{c}(k)$ for all $k>0$. 
Proposition $2 \pi_{d}(k)$ is strictly increasing in $k$.

Proposition 1 states that per-firm profits for members of the competitive fringe are always larger than per-firm profits of cartel members. Proposition 2 says that profits per firm within the cartel increase as the cartel size increases. ${ }^{4}$ An immediate implication of these two propositions is that cartel formation will dominate the competitive situation for both cartel members and members of the competitive fringe.

These propositions can be easily established with the aid of Figure 1. All firms in the industry are identical, each with the marginal cost curve presented by $\mathrm{MC}$ in the diagram. Assume that a cartel forms that contains $k$ firms. Let $A B$ in Figure 1 represent the residual demand schedule for a particular firm in the cartel; that is, it is equation (1) divided by $k$. $C D$ is the corresponding marginal revenue curve for the firm. In order to maximize total profit per firm in the cartel, marginal cost of each firm must equal its marginal revenue (corresponding to the adjusted residual demand schedule). Accordingly, the cartel chooses the price $p^{*}$ and each firm in the cartel produces $q_{d}^{*}$. At the price $p^{*}$, each firm outside the cartel chooses $q_{c}^{*}$.

If a competitive firm had chosen the cartel member's output $q_{d}^{*}$, it would obtain profits equal to $\pi_{d}(k)$. However, as is easily seen in Figure 1, the competitive firm would then find itself with its marginal revenue $p^{*}$ exceeding marginal cost; it can increase profits by expanding output. Formally,

$$
\pi_{d}(k)=p^{*} d_{d}^{*}-\int_{0}^{q_{d}^{*}} C^{\prime}(q) d q<p^{*} q_{c}^{*}-\int_{0}^{q_{c}^{*}} C^{\prime}(q) d q=\pi_{c}(k) .
$$

Proposition 1 has thus been established.

For $k>0$ is is also clear from the diagram that $p^{*}(k)>p_{\text {comp. Since a cartel always has }}$ the option of choosing the competitive price and output, this implies $\pi_{d}(k)>\pi_{\text {comp }}$ for $k>0$. Now consider an increase in the size of the cartel from $k>0$ to $k^{\prime}$. It is certainly feasible for this enlarged cartel to maintain the price at $p^{*}(k)$ and assign to its members production quotas

\footnotetext{
${ }^{4}$ In general, the profits of fringe firms $\pi_{c}(k)$ need not increase with the size of the cartel. Building on the results of this paper, Donsimoni, Economides, and Polemarchakis (1981) have shown that if both demand and marginal cost are linear functions of output, $\pi_{c}(k)$ is increasing in $k$ as well.
} 


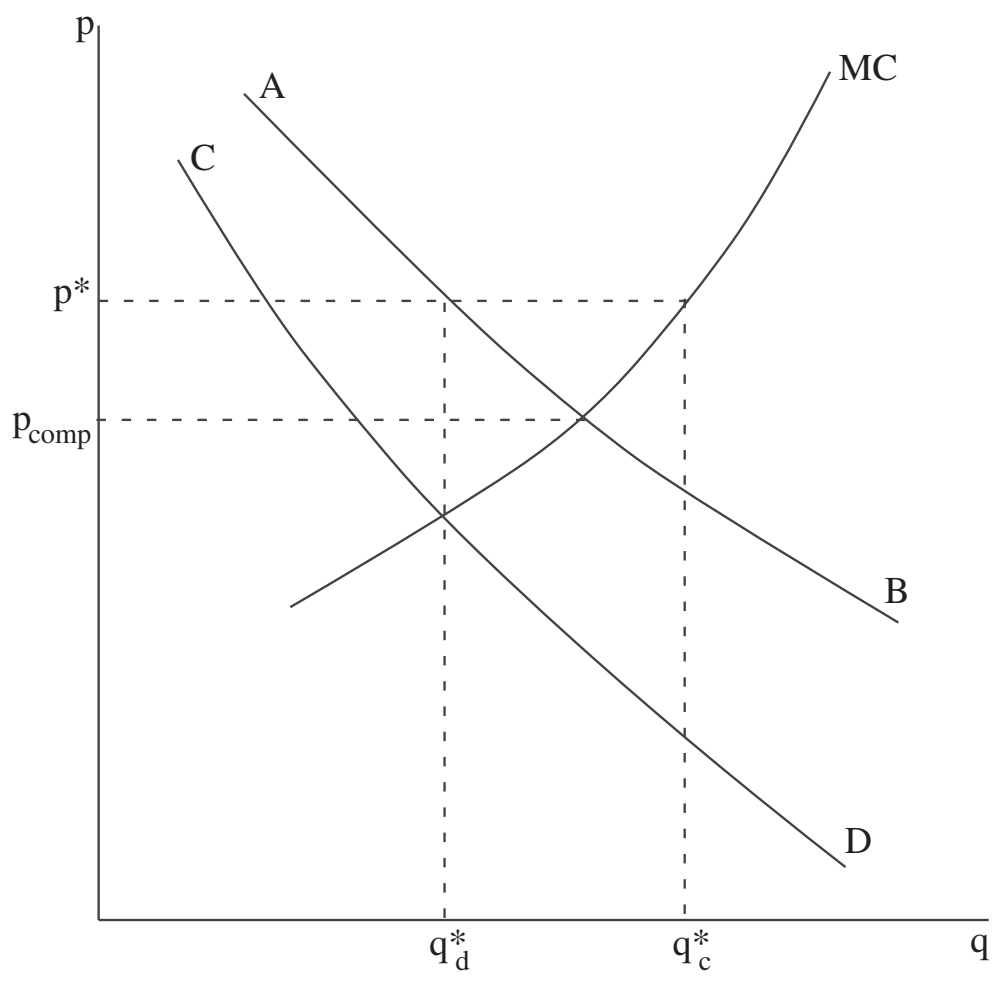

Figure 1:

identical to their respective outputs in the initial situation. Each firm would then have its preentry profits of either $\pi_{d}(k)$ or $\pi_{c}(k)$ with $\pi_{c}(k)>\pi_{d}(k)$ by Proposition 1 . But if this were done, not all members of the enlarged cartel would be producing the same output; marginal cost would vary among members of the cartel. As a consequence, even maintaining the price $p^{*}(k)$ profits per firm in the cartel can be increased, since joint profits are maximal when the production of all members of the cartel is spread uniformly. Since profits can be further increased by choosing the optimal price $p^{*}\left(k^{\prime}\right)$, one must then have finally $\pi_{d}\left(k^{\prime}\right)>\pi_{d}(k)$. This completes the proof of Proposition 2.

In industries with a competitive sector it is natural to model the industry as a continuum of 'infinitesimal' firms represented by the unit interval [0,1]. Propositions 1 and 2 are also valid with a continuum of firms, since the arguments used to establish these results do not depend 
upon the assumption that the number of firms is finite. It is necessary, however, to formulate the problem slightly differently. Because each firm is infinitesimal, the cost functions $C(q)$ and the supply functions $S(p)$ of the fringe firms should be interpreted as density functions. With the proposition $\alpha, \alpha \in[0,1]$, of the firms in the dominant cartel, the residual demand curve is

$$
\widetilde{\mathrm{RD}}(\alpha, p) \equiv D(p)-(1-\alpha) S(p)
$$

where the overhead tilde is used to differentiate this expression from (1). To obtain the curve $A B$ in Figure 1, which is in per-firm terms, (2) is divided by $\alpha$. With these modifications the analysis can proceed as before.

Propositions 1 and 2 allow us to conclude that there is a general interest in the existence of a cartel. Furthermore, cartel members will always wish to encourage part of the fringe to join the cartel. However, the benefits of cartel formation are never evenly distributed between members of the cartel and members of the competitive fringe; the latter are always better treated than the former!

\section{Cartel stability}

The results of the previous section suggest that there will be an intrinsic difficulty in convincing firms to constitute the dominant cartel. This phenomenon has been observed by Stigler (1950, 25-26) in a discussion of mergers. 'The major difficulty in forming a merger is that it is more profitable to be outside a merger than to be a participant. The outsider sells at the same price but at the much larger output at which marginal cost equals price. Hence, the promoter of a merger is likely to receive much encouragement from each firm - almost every encouragement, in fact, except participation.'

A related difficulty appears should a cartel somehow be formed. The cartel firms reduce output (compared to the competitive outcome) in order to raise the price. The fringe firms are 'free-riders' and consequently receive higher profits than members of the cartel. This situation suggests that the cartel will not be viable, since there will be a temptation for firms in the cartel 
to defect to the fringe. Stigler (1964) also recognized this problem, arguing that the instability would be pervasive in oligopoly models.

These arguments are incomplete, however, because they ignore the impact on price and hence on profits of the movement of a firm either into or from the cartel. With a continuum of firms such a movement has a negligible impact on price and on per-firm profits (both in the cartel and in the competitive fringe); consequently, both problems identified above affect the price-leadership model. With a finite number of firms, the situation is quite different.

When considering the stability of a dominant cartel, it is useful to distinguish between internal and external stability. A cartel with $k$ members is said to be internally stable if $k \geq 1$ and

$$
\pi_{c}(k-1) \leq \pi_{d}(k)
$$

Although in our model a fringe firm earns higher profits than a cartel firm, if a cartel member left an internally stable cartel, it would find that its departure would depress the price sufficiently that the profits it would receive in the fringe would be no higher than it enjoyed as part of the cartel. A cartel is said to be externally stable if $k \leq n-1$ and

$$
\pi_{d}(k+1) \leq \pi_{c}(k)
$$

With an externally stable cartel there is no incentive for a new firm to join the cartel, since the resulting increase in price would not be sufficient to raise a cartel member's profits above what fringe firms currently receive. As a convention we shall consider the null cartel, $k=0$, to be internally stable and the monopoly cartel, $k=n$, to be externally stable. A cartel that is both internally and externally stable will simply be called stable. Neglecting situations where (3) and (4) are satisfied with equality, a cartel with $k$ members is internally stable if and only if the cartel with $k-1$ members is externally unstable.

In surprising contrast to the instability associated with a continuum of firms, when the number of firms is finite it is always possible to find a group of firms that can form a stable cartel. 
Theorem 1 With $n$ finite, there exists a $k \in\{1, \cdots, n\}$ such that (3) and (4) hold; there is always a stable cartel.

The proof of the theorem proceeds by establishing an algorithm to find a stable cartel. By Proposition 2 the cartel with $k=0$ is externally unstable and the cartel with $k=1$ is internally stable. If $k=1$ is externally stable, a stable cartel has been found. If not, consider $k=2$. It will be internally stable; for otherwise the procedure would have stopped at $k=1$. If $k=2$ is externally stable, the search is complete. Continuing in his fashion, either a stable cartel is found with $k<n$ or the algorithm arrives at $k=n$. In the latter case $n$ will be internally stable, and since there are no further firms to join the cartel, the monopoly cartel is stable. Hence, the theorem is established. ${ }^{5}$

Our stability theorem suggests that the observations that opened this section are of limited applicability with a finite number of firms. If $k$ firms constitute a stable cartel, a cartel with $k-1$ firms will be externally unstable. Thus, if there are only $k-1$ firms in the cartel there is an incentive for one fringe firm to join or merge with the existing cartel members. Since a stable cartel is internally stable, the mere presence of higher profits in the fringe will not be sufficient to encourage a defection, as the increased profits from expanded production will be overcompensated by the reduction in profits which results from the fall in price. Such internal stability is not possible with a continuum of firms.

\section{Stable cartels and industry size}

The contrast between the stability found with a number of firms and the instability found with a continuum of firms invites an explanation. While it is beyond the scope of this article to provide a detailed examination of this issue, a few remarks will provide further intuition for our results.

One reason for these diverging conclusions is technical in nature. In both the finite and continuum cases there is a general interest in having a cartel form. With a finite number of

\footnotetext{
${ }^{5}$ If, instead of having 'marginal' exits from the cartel it is possible to restrict such movements to large blocks, one may introduce alternative stability notions, and a different stability analysis should be carried out.
} 
firms this leads to the internal stability of the cartel with $k=1$, the smallest non-null cartel. With a continuum of firms there is no smallest non-null cartel. Coupled with the negligible impact the exit of a cartel member has one price and profits, no cartel will be internally stable.

While our theorem demonstrates that a stable cartel always exists in the finite case, this by itself does not provide any insight into the size of the cartel relative to the size of the competitive fringe. With a finite number of firms, the larger the industry, the smaller the expected impact of exit on price and profits, thus increasing the likelihood of a particular cartel being internally unstable. This reasoning suggests that the fraction of firms in a stable cartel would asymptotically approach zero as the number of firms approaches infinity.

The crucial step in this line of reasoning is the belief that the exit of a firm from the cartel in a large industry will have a small effect on price and profits. Whether this is in fact true in general is an open question. Below we present an example that does satisfy this property.

One particular way to develop asymptotic results is to increase a finite economy without limit by means of a replication process. On the supply side, since all firms are identical, doubling the number of firms from 2 to $2 n$ simply results in $2 n$ firms of the same type as found in the $n$-firm industry. Demand is also replicated; so at each price the quantity demanded is also doubled. Therefore the market demand curve, denoted $\bar{D}(n, p)$, is also a function of $n$ with

$$
\bar{D}(n, p)=n \bar{D}(1, p)
$$

This kind of replication not only leaves the competitive price invariant, it also implies that profits per firm (when price is chosen optimally) depend only on the fraction of firms in the dominant cartel.

Our example utilizes this kind of replica economy. Aggregate demand is

$$
\bar{D}(n, p)=n(1-p)
$$

while each firm has the cost function

$$
C(q)=\frac{1}{2} q^{2}
$$

For this example, the only stable cartel size is $k=3$ whenever there are at least four firms in 
the industry. ${ }^{6}$ Hence, in our example the fraction of firms in a stable cartel decreases with the size of the industry and tends to zero. As noted above, for the price-leadership model it remains an open question whether this conclusion holds with more general demand and cost curves. ${ }^{7}$

\section{Conclusions}

To summarize, for the price-leadership model we have found that there is a general interest in having a cartel form and per-firm profits in the cartel increase with its size. However, the competitive fringe reaps a disproportionate share of the benefits. When the impact on price of exit from (or entry to) the cartel is taken into account, a stable cartel always exists when there are a finite number of firms, despite the free-riding of the fringe, but never exists for a continuum of firms. We may thus conclude that the crucial feature determining whether a cartel exhibiting price-leadership behaviour will be stable is the size of the effect on price and profits that the addition or loss of a cartel member would have.

In large finite industries, we would expect that only cartels containing a small fraction of the firms would be stable if this effect is small. In such cases, because the cartel is relatively ineffective, the existence of a cartel would not significantly alter the competitive arrangement, yielding little incentive for cartel formation. Whether in such industries the effect of exit is indeed small requires further analysis before any general conclusions can be reached.

Many of the limitations of the present analysis are inherent in the price-leadership model.

\footnotetext{
${ }^{6}$ A detailed discussion of this example, as well as a proof of this statement, is contained in an appendix to the manuscript version of this article, Discussion Paper No. 82-22, Department of Economics, University of British Columbia.

${ }^{7}$ Commenting on cartel formation in a general oligopolistic model, Postlewaite and J. Roberts (1977) argue that with sufficient continuity assumptions, which they expect to be satisfied in non-pathological situations, the hypothesis of asymptotic instability is true. K. Roberts (1980), in a general equilibrium model of monopolistically competitive firms, argues that even in the limit oligopolistic power may persist as firms are able to exploit nonpathological 'irregularities in the economic structure.' Our example has the property that fringe profits $\pi_{c}(k)$ are increasing in the size of the cartel (cf. fn. 4). Perhaps non-monotonicity of $\pi_{c}(k)$ is an 'irregularity' that could lead to significant price changes when a single firm exits the cartel, even in a large industry.
} 
Only two strategies are open to firms: either they join the competitive fringe and behave as price-takers of they join the cartel where they joint profit maximize. Intermediate forms of behaviour are excluded by assumption. If more general models of dominant cartels are considered, the strategic options can be made more realistic, different cost conditions can be envisaged, ${ }^{8}$ alternative conjectures concerning fringe behaviour can be entertained, ${ }^{9}$ and a dynamic framework can be employed. ${ }^{10}$ Obviously, further research is necessary before we can determine the generality of our results.

\section{References}

Aumann, R., 1973. Disadvantageous monopolies. Journal of Economic Theory, 6, 1-11.

Donsimoni, M.-P., Economides, N.S. and H.M. Polemarchakis, 1981. Stable cartels. Document de travail no. 8112, Institut National de la Statistique et des Etudes Economiques.

Jaskold Gabszewicz, J. and J.H. Drèze, 1971. Syndicates of traders in an exchange economy. In H.W. Kuhn and G. Szegö (eds.), Differential Games and Related Topics. Amsterdam, NorthHolland.

Lewis, T.R. and R. Schmalensee, 1980. Cartel and oligopoly pricing of nonreplenishable natural resources. In P.-T. Liu (ed.), Dynamic Optimization and Mathematical Economics. New York, Plenum.

\footnotetext{
${ }^{8}$ It would be of interest to determine the implications for our results of having a small (as opposed to zero) efficient scale of operations as in Novshek (1980).

${ }^{9}$ This modification of the model has been explored by Donsimoni et al. (1981).

${ }^{10}$ Our model is static. Salant (1976), Lewis and Schmalensee (1980), and a number of other authors have employed the price-leadership model to study the exploitation of a non-renewable resource in a dynamic framework. In these models the fringe responds competitively to the price trajectory announced by the cartel. Free-riding by the fringe is observed with the consequence (if all firms have equal reserves) that fringe firms exhaust their stocks first, thus leaving the cartel with a period when it is a complete monopolist. The structure of this dynamic problem is sufficiently different from the static problem considered here that the argument used to establish our stability theorem is not applicable.
} 
Markham, J.W., 1951. The nature and significance of price-leadership. American Economic Review, 41, 891-905.

Novshek, W., 1980. Cournot equilibrium with free entry. Review of Economic Studies, 47, 473-486.

Postlewaite, A. and J. Roberts, 1977. A note on the stability of large cartels. Econometrica, 45, $1877-1878$.

Roberts, K., 1980. The limit points of monopolistic competition. Journal of Economic Theory, $22,256-278$.

Salant, S.W., 1976. Exhaustible resources and industrial structure: a Nash Cournot approach to the world oil market. Journal of Political Economy, 84, 1079-1093.

Scherer, F.M., 1970. Industrial Market Structure and Economic Performance. Chicago: Rand McNally.

Stigler, G.J., 1950. Monopoly and oligopoly by merger. American Economic Review Papers and Proceedings, 40, 23-34.

Stigler, G.J., 1964. A theory of oligopoly. Journal of Political Economy, 72, 44-61.

Worcester, Jr, D., 1957. Why "dominant firms" decline. Journal of Political Economy, 65, $338-346$. 